\title{
THE PATHOLOGY AND IMMUNOLOGY OF BORDETELLA PERTUSSIS INFECTION
}

\author{
L. B. HoLT* \\ Division of Immunological Products Control, National Institute for Medical Research, \\ Hampstead, London, NW3
}

\section{Plates XXII AND XXIII}

IN common with many other mucous membranes, the nasopharynx is covered by a film of mucus kept in continuous motion by the cilia arising from its epithelium. To avoid exclusion and removal from the nasopharyngeal surface, organisms like Bordetella pertussis must therefore be able to anchor themselves to some fixed structure there. It has been shown that in whooping cough in children Bord. pertussis has a marked tendency to attach itself to the cilia of the nasopharynx (Rich, 1932), and in intracerebral infection in mice to the cilia of the ventricular ependyma (Berenbaum, Ungar and Stevens, 1960; Iida et al., 1962). In neither of these situations is experimental examination of the local circumstances at all easy, so it is necessary to consider a parallel case and devise a comparable system free from this defect.

The comparable system is the attachment of influenza virus to red cells (Hirst, 1941, $1942 a$ and $b$ ). The virus particle contains in its surface a haemagglutinin through which it is attached to the red cell, and in addition an esterase, N-acetylneuraminidase, which at $37^{\circ} \mathrm{C}$ hydrolyses sialic acid from the red-cell glycoprotein with simultaneous release of the virus particle (Gottschalk, 1958). Specific anti-influenza antisera prevent the attachment of the virus particle to the red cell and the consequent haemagglutination, and this anti-haemagglutination activity runs parallel to the capacity of sera to neutralise influenza virus in intranasal infection tests (Meiklejohn et al., 1952; Bell et al., 1957; Tyrrell, 1967). Clinical immunity to influenza virus thus appears to be mediated by specific haemagglutination-inhibitor, but in addition many substances containing sialic acid non-specifically inhibit haemagglutination of red cells.

In the nasopharynx, clinical immunity appears to depend on a locally produced secretory immunoglobulin IgA, 11S (Tomasi and Bienenstock, 1968), which prevents attachment of the virus to the cilia of the nasopharynx-a situation analogous with that in the haemagglutinating system for the virus.

Unfortunately Bord. pertussis does not readily adhere to washed red cells of man (type O), rabbit, horse, guinea-pig, mouse or ox, so these could not be used as a model of the susceptible cell $\dagger$. I found, however, that it does

Received 11 Oct. 1971; accepted 9 Mar. 1972.

* Honorary Research Worker.

+ Bord. pertussis haemagglutinin is not a property of the microbe but of a substance released from it. The " substrate" on the surface of red cells agglutinated by this haemagglutinin was found to be destroyed by digestion of the red cells with mollusc $\beta$-glucuronidase, analogous to the action of RDE on red cells in respect of influenza virus.

J. MED. MICROBIOL.-VOL. 5 (1972) 
adhere readily and strongly to tissue-culture cell-lines of human lung fibroblasts (MRC-5), monkey kidney cells and a vocal cord epithelioma (Hep 2), but not to those of a cervical carcinoma (HeLa). Moreover, incubation of Bord. pertussis with adult human serum before adding it to a culture of MRC-5 abolished its capacity to adhere to the tissue-culture cells. As this seemed to offer a promising comparison with the in-vivo activity of Bord.pertussis, I used several different tissue-culture cell-lines and some tracheal organ-cultures to examine this adhesive property of a number of nasopharyngeal pathogens, particularly Bord. pertussis, and to assay the anti-adhesive property of sera and salivary secretions.

\section{MATERIALS AND METHODS}

Strains. Thirteen strains of Bord. pertussis previously used (Holt, 1968) and 17 others provided by $\mathrm{Dr}$ J. Cameron were studied. Six other nasopharyngeal pathogens were included: Bord. parapertussis (strain B1824) and Bord. bronchiseptica (strain B8760), both from Dr Vera Spasojević, Belgrade, Staphylococcus aureus (strain Wood 46), Corynebacterium diphtheriae (strain G12/6), Streptococcus pneumoniae (strain T3, no. NCTC7978), Strep. pyogenes (group-A streptococcus no. NCTC2218) and Haemophilus influenzae type b (no. NCTC7279).

Stock cultures for long-term storage were freeze-dried in 5 per cent. skim milk and sealed in vacuo. For short-term storage a suspension was made up in neutralised 1 per cent. Casamino Acids (CA) at a density of about 20 opacity units, mixed with an equal volume of sterile glycerol and stored at $-25^{\circ} \mathrm{C}$; cultures stored in this way grew in $c .40 \mathrm{hr}$ on subculture. For $H$. influenzae it was found that addition of 5 per cent. by volume of sheep blood to the CA suspension of organisms improved viability during storage at $-25^{\circ} \mathrm{C}$.

Bacterial cultures. Strains of Bord.pertussis and parapertussis were grown on a substitute Bordet-Gengou medium (SBG) -Casamino Acids (Difco technical) $6 \mathrm{~g}$; glutathione 0.1 g; $\mathrm{NaCl} 6 \mathrm{~g} ; \mathrm{FeCl}_{3} .6 \mathrm{H}_{2} \mathrm{O}$ (AR) 1.25 per cent. w/v $+\mathrm{CuCl}_{2} .6 \mathrm{H}_{2} \mathrm{O}$ (AR) 1.25 per cent. w/v in $\mathrm{N}-\mathrm{HCl}, 1 \mathrm{ml}$; distilled water $1000 \mathrm{ml}$; adjust the $p \mathrm{H}$ to 6.8 , dispense in 100-ml quantities into bottles containing $2 \mathrm{~g}$ Difco agar and sterilise in the autoclave for $15 \mathrm{~min}$. at $121^{\circ} \mathrm{C}$. For use melt this basal medium, cool it to $50^{\circ} \mathrm{C}$ and add $25 \mathrm{ml}$ sheep blood; make four SBG plates in 9-cm plastic petri dishes from each bottle.

The medium used for $H$. influenzae and the streptococci was that of Holt (1962). All cultures were incubated at $36^{\circ} \mathrm{C}$, usually for $18 \mathrm{hr}$ only, before they were subcultured.

Agglutination. An agglutination apparatus similar to that of Miller and Silverberg (1939) was used.

Cell-lines. MRC-5, HeLa, Hep 2 and monkey kidney cells (MKC) were obtained as seed suspensions from the Tissue Culture section of the Division of Immunological Products Control in bottles each containing $c .2 .5 \times 10^{6}$ cells. These $2.5 \times 10^{6}$ cells were suspended in $100 \mathrm{ml}$ Eagles' complete medium, containing 10 per cent. calf serum as well as penicillin and streptomycin; 3-ml volumes of the suspension were dispensed into 25 -mm-diameter flatbottomed bottles $47 \mathrm{~mm}$ tall, with a rubber lined screw-cap of $18 \mathrm{~mm}$ inside diameter. One circular glass coverslip ( $16 \mathrm{~mm}$ in diameter) was placed in each bottle, and the assembly was autoclaved for $15 \mathrm{~min}$. at $115^{\circ} \mathrm{C}$.

The cell seed was incubated at $36^{\circ} \mathrm{C}$ for $48 \mathrm{hr}$ and the cultures were washed twice with $8 \mathrm{ml}$ of Hanks' solution to remove most of the culture medium. Confluent growth proved unsuitable, as adhesion of bacteria was, for some unexplained reason, poor.

Cell-line infection technique. From a third SBG culture of Bord. pertussis strain 18/323, unless otherwise stated, a suspension was made in 1 per cent. $\mathrm{CA}$ in 0.5 per cent. $\mathrm{NaCl}$ at $p \mathrm{H} 7.6$ plus 1 per cent. $\mathrm{v} / \mathrm{v}$ calf serum to give a density of 10 opacity units $\left(10^{9}\right.$ organisms per $\mathrm{ml}$, or $2 \frac{1}{2}$ on the Brown opacity tube scale). This suspension was diluted 1 in 20 in 1 per cent. $\mathrm{CA}+1$ per cent. calf serum (CA.CS), and $2 \mathrm{ml}$ of the dilution was placed on one $48 \mathrm{hr}$ culture of MRC-5 fibroblasts and the mixture was incubated for $4 \mathrm{hr}$ at $36^{\circ} \mathrm{C}$. 
Serum and saliva samples from a vaccinated Taiwan monkey. A Taiwan monkey (Macacus cyclopsis) was immunised because Huang et al. (1962) had been unusually successful in producing experimental whooping cough in this species. Samples of blood and saliva were obtained from a monkey sedated with $2 \mathrm{mg}$ Sernylan per $\mathrm{kg}$ body weight before, and at various times after, Bord. pertussis vaccine made from heat-killed cultures of strain CN127 had been sprayed with a Shandon Laboratory Spray Gun at a density of 20 OU into the nostrils $(0.25 \mathrm{ml}$ each) and into the mouth $(0.5 \mathrm{ml})$ with the tongue depressed with a wooden spatula.

Saliva samples were obtained by spitting into centrifuge tubes. They were centrifuged at $500 \mathrm{~g}$ for $15 \mathrm{~min}$., and the clear supernatant was separated from the glutinous deposit. For most experiments $5 \mathrm{ml}$ was adequate.

Assay of anti-adhesive $(A A)$ titre of serum and saliva. The technique was essentially that of Spasojević (1962) for the assay of the protective titre of immune sera by injecting mixtures of live organisms and dilutions of inactivated sera into the brain of mice (the "i.c. mix technique "); addition of the mixtures to living fibroblast cell cultures replaced injection into mouse brain.

Human and animal sera were inactivated by heating at $56^{\circ} \mathrm{C}$ for $30 \mathrm{~min}$. Saliva samples were not heated, since haemolytic complement was not detected in them. Dilutions of test material were made in $1 \mathrm{ml}$ amounts in CA.CS in 5-ml screw-capped bottles. The highest concentration of saliva tested was a 1 in 3 dilution, since undiluted saliva detached fibroblasts from the glass; serum may usually be tested undiluted. $1 \mathrm{ml}$ of serum or saliva dilution was added to $1 \mathrm{ml}$ of the CA.CS suspension of the organism under test. The mixture was incubated at $36^{\circ} \mathrm{C}$ for $1 \mathrm{hr}$ and then added to a washed $48-\mathrm{hr}$ culture of live fibroblasts, with which it was incubated for a further $4 \mathrm{hr}$ at $36^{\circ} \mathrm{C}$.

The treated cell-culture was washed with two changes of Hanks' solution and dehydrated in graded concentrations of ethanol and for $10 \mathrm{~min}$. in a mixture of equal volumes of ether and ethanol. The films were then rehydrated with the same graded concentrations of ethanol in reverse order and taken finally into distilled water. Giemsa's stain $(1 \mathrm{ml})$ was then added to the wet film, which was allowed to stain for at least $10 \mathrm{~min}$.; the glass disks were then removed from the bottles and washed once with neutral distilled water, dehydrated in (i) 90 per cent. acetone, (ii) 90 per cent. acetone +10 per cent. xylol, (iii) 70 per cent. acetone + 30 per cent. xylol, and (iv) 50 per cent. acetone +50 per cent. xylol, and mounted in DPX (George Gurr, Ltd, London) on a microscope slide 0.8-1.0 mm thick.

Microscopy. Direct and dark-ground illumination were used. With direct illumination, nuclei appeared pink and organisms blue; with dark-ground illumination, which gave superior viewing, nuclei appeared pink with well-marked nuclear membranes, the cytoplasmic processes were greenish-grey and the organisms, mostly in short chains, a bright golden-yellow with darker centre.

Three degrees of adherence of organisms to the filaments of fibroblasts were recognised: (i) adhesion equal to that given by the positive control $(1 \mathrm{ml} \mathrm{CA}$. CS bacterial suspension + $1 \mathrm{ml} \mathrm{CA}$ ); (ii) no adhesion to fibroblasts, where the distribution of organisms over the culture is the same as over the uninvaded coverslip, and (iii) a few adherent organisms, approximately one-tenth of the number adherent in the positive control. Degree (iii) is the arbitrary endpoint used in this work, and decrease in adherence from degree (i) to degree (ii) may sometimes occur when the amount of serum used is increased two-fold.

Preparation of rabbit anti-Bord. pertussis antisera. Normal cross-bred 2-kg rabbits were bled from an ear-vein, given one injection of $10^{9}$ killed organisms by subcutaneous injection and a further three similar injections intravenously at 10-day intervals thereafter. A second bleeding was made 12 days after the fourth injection; the sera were inactivated by heating at $56^{\circ} \mathrm{C}$ for $30 \mathrm{~min}$. and stored at $-25^{\circ} \mathrm{C}$ without preservative.

Preliminary work showed that the conditions specified above are satisfactory, and indicated also that the culture of fibroblasts should not be allowed to become too alkaline through loss of $\mathrm{CO}_{2}$ because such cells are readily detached from glass. On the other hand, as the $p \mathrm{H}$ of cultures approached the isoelectric point of the bacteria, fewer and fewer bacteria became adherent, and at $p \mathrm{H} 5$ no Bord. pertussis adhered at all. For the bacteria-serum mixtures, 


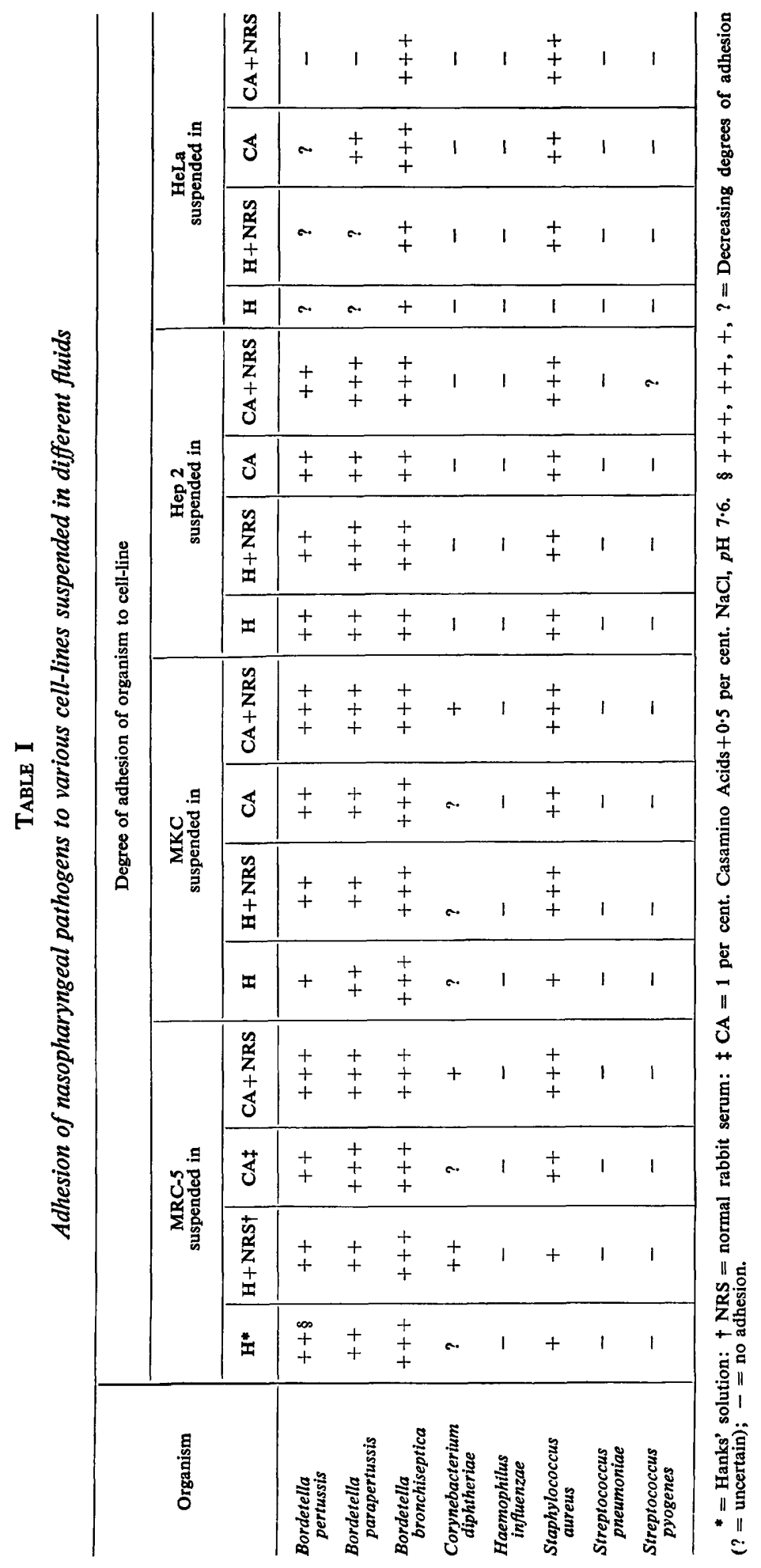


BORD. PERTUSSIS INFECTION AND IMMUNITY

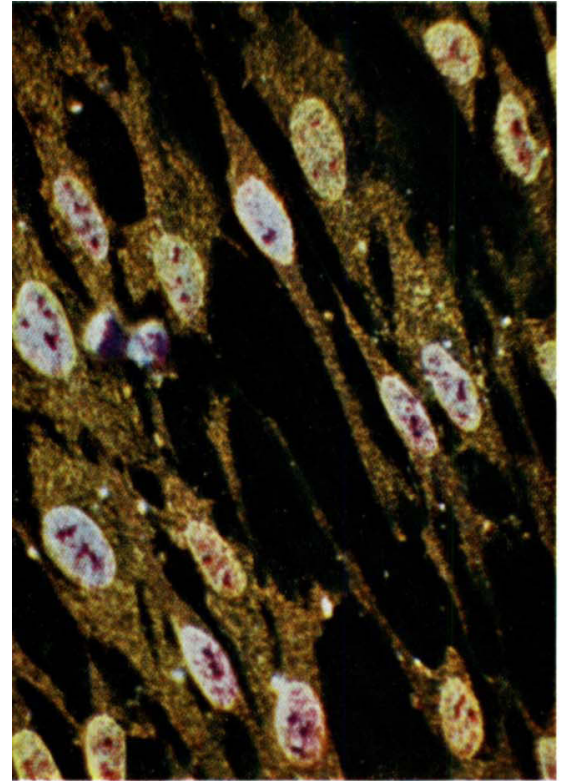

FIG. 1. - Normal cultured fibroblasts. Giemsa, dark-ground (G, DG). $\times 375$.

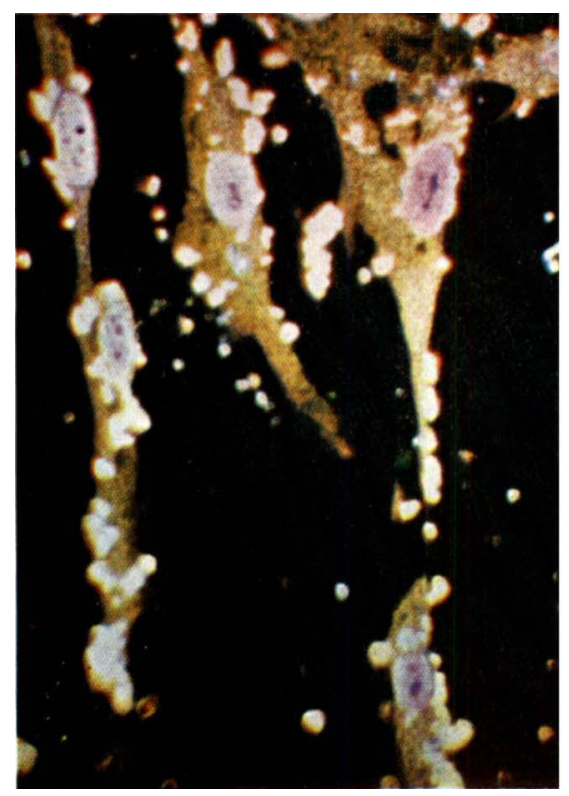

FIG. 3.-Cultured fibroblasts infected with Staphylococcus aureus, strain Wood 46. G, DG. $\times 375$.

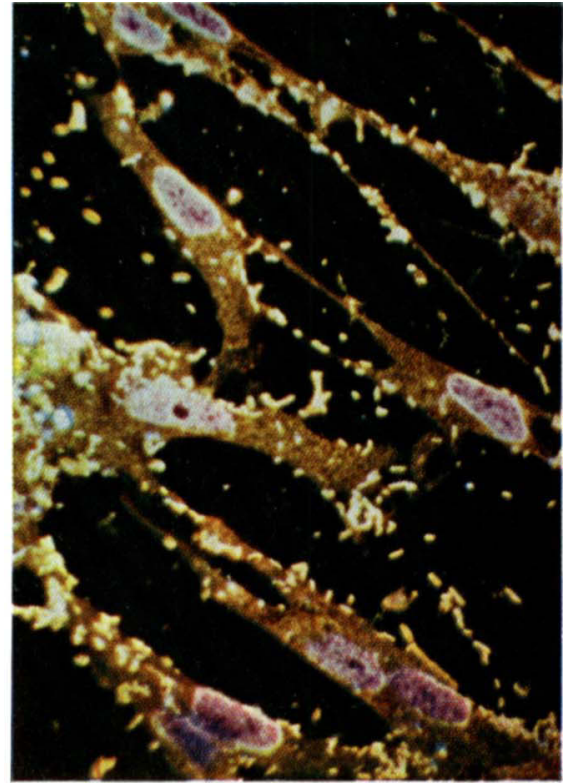

FIG. 2.-Cultured fibroblasts infected with Bordetella pertussis. G, DG. $\times 375$.

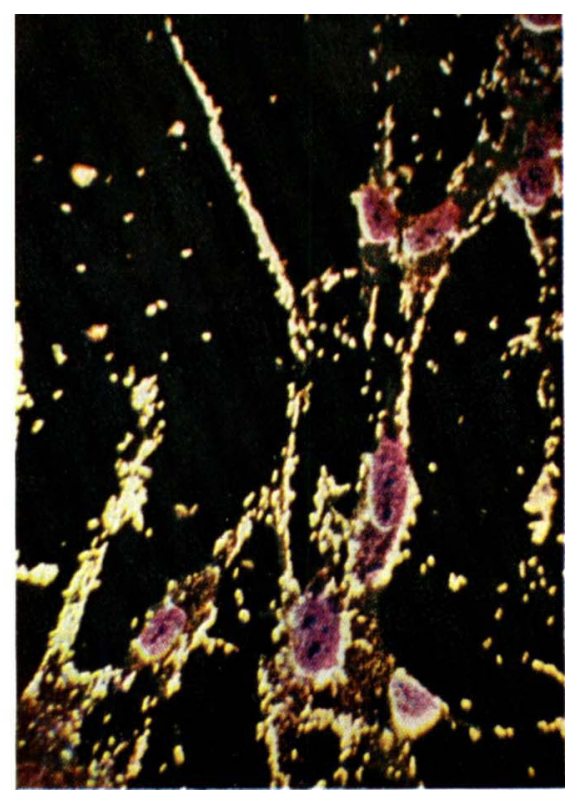

FIG. 4.-Cultured fibroblasts infected with Bordetella bronchiseptica. G, DG. $\times 375$. 
BORD. PERTUSSIS INFECTION AND IMMUNITY

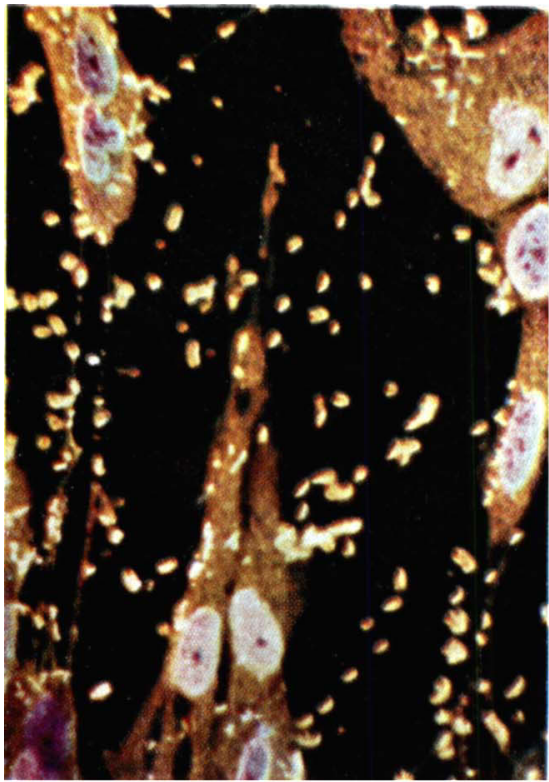

FIG. 5.-Cultured fibroblasts infected with Bordetella pertussis pre-treated with antiserum diluted 1 in 45 . G, DG. $\times 375$.

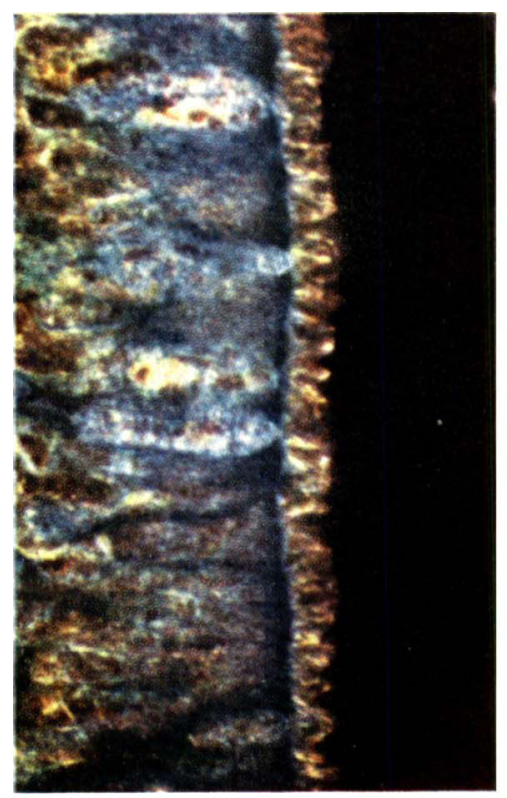

FIG. 7.-Normal rhesus monkey trachea. G, DG. $\times 375$.

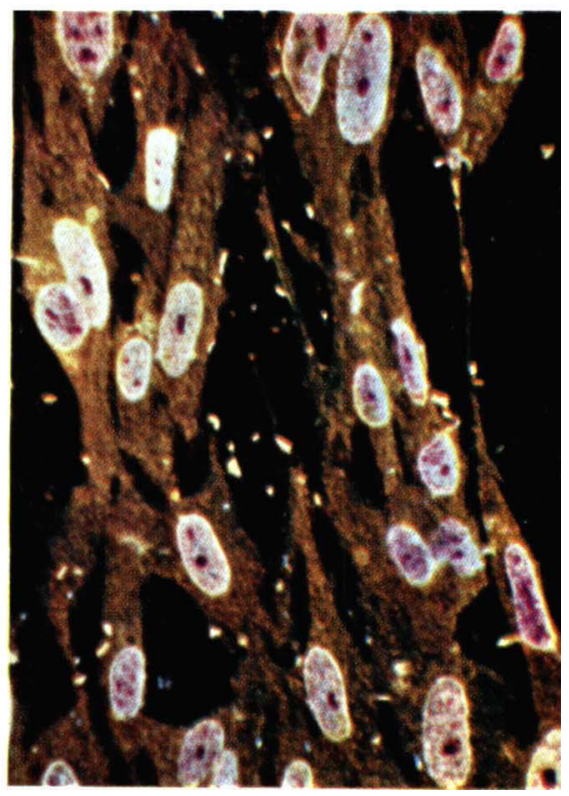

FIG. 6.-As in fig. 5 but antiserum diluted 1 in 15 . G, DG. $\times 375$.

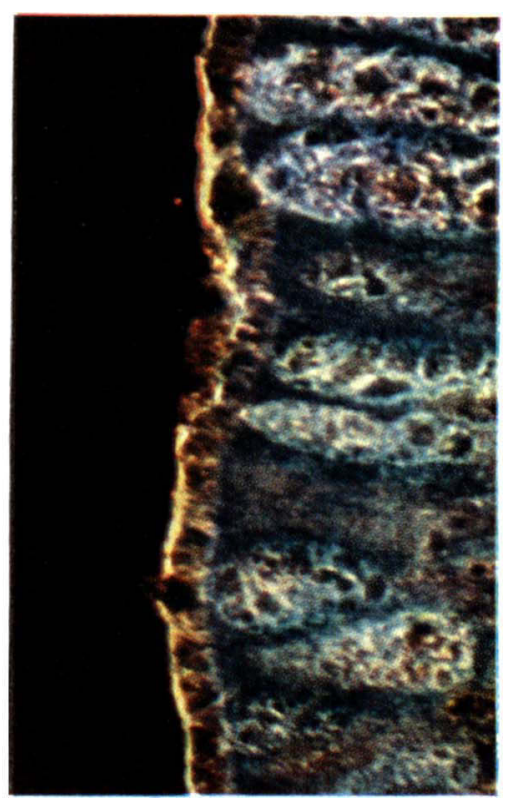

FIG. 8.-Rhesus monkey trachea, experimentally infected with Bordetella pertussis. $\mathrm{G}, \mathrm{DG}$. $\times 375$. 
the greatest AA titre was obtained when the mixture was adjusted to $p \mathrm{H} \mathrm{7.5;} \mathrm{the} \mathrm{ratio} \mathrm{between}$ titres at $p \mathrm{H} \mathrm{7.5}$ and at $p \mathrm{H} 5.5$ might be as much as $4: 1$.

The addition of 1 per cent. normal rabbit or, better, normal calf serum, to the serum diluent and the challenge strain gave better adhesion of organisms to fibroblasts and less adhesion of bacteria to glass. Calf serum was used as a routine.

Monkey trachea experiments. Tracheae were excised from rhesus monkeys within $30 \mathrm{~min}$. after the monkeys had been killed, and pieces of trachea about $50 \mathrm{~mm}$ long were placed in 25-ml screw-capped bottles (Universal Containers), covered with Hanks' solution and left at room temperature for $1 \mathrm{hr}$ to allow the Sernylan used for sedation to diffuse out. From each such length, 4-5 rings each about $5 \mathrm{~mm}$ long were cut off. In the early experiments the rings were placed in a suspension of Bord. pertussis in CA, but adhesion of the organisms was very poor, even when the mixtures were incubated at $36^{\circ} \mathrm{C}$ for $2 \mathrm{hr}$. Much more adhesion occurred when the suspension of live organisms was sprayed through the ring of trachea with a Shandon Laboratory Spray Gun. The density of the suspension of organisms was $1 \mathrm{OU}$ and the spray time $c .10 \mathrm{~s}$.

The tracheal rings were fixed in Bouin's fluid for $24 \mathrm{hr}$, washed in 90 per cent. ethanol to remove picric acid, and embedded in paraffin wax in the usual way. 5- $\mu \mathrm{m}$ sections were stained for not more than $10 \mathrm{~min}$. with the same Giemsa's stain as that used for the fibroblast cultures, and dehydrated, fixed and mounted as the cultures were. In a positive section the organisms were clearly seen, apparently adhering to the tracheal cilia.

Passive immunity tests. For the measurement of the antibody responsible for passive protection of mice against intracerebral infection, the technique of Dolby and Standfast (1958) was used. About 150 LD50 Bord. pertussis strain $18 / 323$ in $0.025 \mathrm{ml}$ were inoculated intracerebrally into NIH mice weighing $14-17 \mathrm{~g} ; 48 \mathrm{hr}$ later the mice were given $0.5 \mathrm{ml}$ of graded doses of the serum under test by the intraperitoneal route. For the i.c. mix technique of Spasojević, her method was followed precisely. In both tests the 50 per cent. protective dose (PD50) of the sera was determined from probits of percentage survival plotted against $\log _{10}$ doses $(\mathrm{ml})$.

\section{RESULTS}

\section{The adhesion of Bordetella pertussis to fibroblasts (figs. 1 and 2)}

Obviously, any use of fibroblast cell cultures in a model system for the early stages of infection in natural whooping cough assumes that the surface of fibroblasts resembles that of nasopharyngeal cilia, and that Bord. pertussis isolated from cases of whooping cough-as all the strains used had beenwill adhere to these cell cultures. All but one of the 30 strains did indeed show marked adherence, and even the solitary exception (strain B149) showed weak adhesion. It was also found that preservative-free heat-killed Bord. pertussis vaccine readily adhered to the fibroblasts, but not a boiled vaccine.

Because I had available a number of other nasopharyngeal pathogens and several other cell-lines (see Materials and methods, p. 408), it was possible to determine whether the adhesion effect was specific to either organism or cell, and because it had already been accidentally observed that the addition of dilutions of normal rabbit serum used for serum control purposes notably increased adhesion of Bord. pertussis to fibroblasts, several different suspending fluids were also tested.

Table I shows that four organisms ( $C$. diphtheriae, $H$. influenzae, Strep. pneumoniae and Strep. pyogenes) failed to adhere to the four cell-lines in any of the suspending fluids. Of the four other organisms, Bord. bronchiseptica (fig. 3) was adherent to all cell-lines in all suspending fluids; Bord. pertussis and 


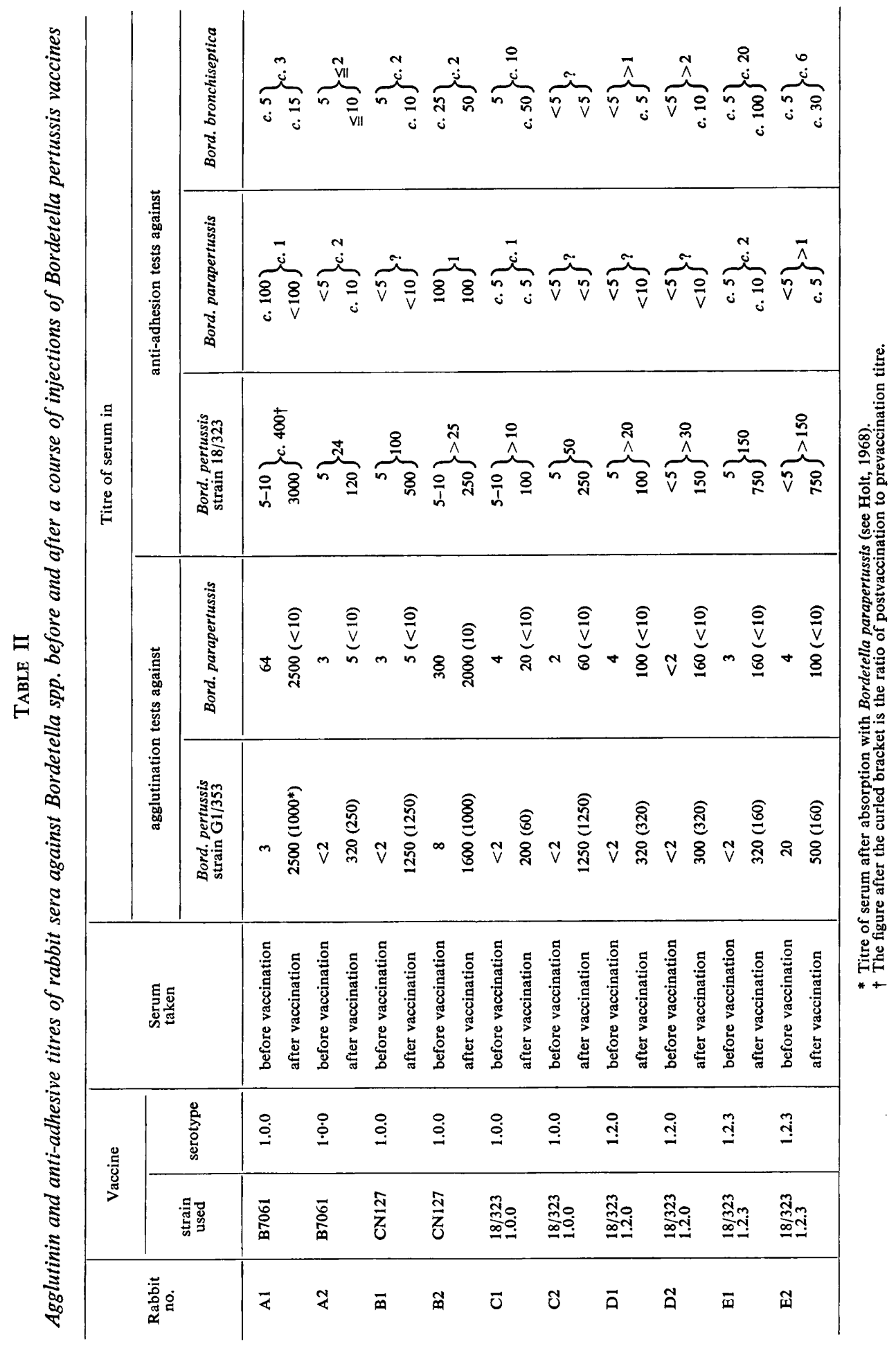


parapertussis were adherent to cell-lines MRC-5, MKC and Hep 2 in all suspending fluids; Staph. aureus (fig. 4) adhered to all cell-lines in all fluids except Hanks' solution, in which it failed to adhere to HeLa cells. The reasons for these differences are not known.

\section{Specificity of the anti-adhesive $(A A)$ power of immune sera}

Pre- and post-vaccination sera from ten rabbits previously used (Holt, 1968) were tested for their AA power against Bord. pertussis, parapertussis and bronchiseptica (table II). Injection of Bord. pertussis vaccines made from five different strains increased the AA titre significantly only against Bord. pertussis (see figs. 5 and 6).

Sera were obtained from rabbits before and 12 days after vaccination with (a) Pillemer's SPA (Pillemer, Blum and Lepow, 1954), (b) Bord. parapertussis vaccine, $(c)$ Bord. bronchiseptica vaccine, and $(d)$ a vaccine made from strain $18 / 323$ and then boiled. Each serum was tested for agglutination titre against Bord. pertussis strains Pillemer 134 and 18/323, and against Bord. parapertussis and Bord. bronchiseptica; and for their AA titre against one strain of each Bordetella species (table III). The AA titres of the sera were species-specific, and boiled vaccine did not induce either agglutinating or anti-adhesive antibody in significant amount.

\section{Failure of immune sera to detach adherent organisms}

Tests to determine whether immune sera would detach bacteria already adherent to fibroblasts showed that the addition of serum many times more concentrated than was required to prevent adhesion failed to detach adherent bacteria even after 2 hours' incubation.

Dependence of the estimated AA titre of an immune serum on the strain of Bord. pertussis used in the test

The AA titre of a given serum was about the same against strains $18 / 323$, G1353Z and CN127, but against strain Pillemer 134 it was only about onetenth of that against other strains.

\section{Effect on the AA titre of sera of the number of organisms used in the test}

The AA titre of a serum varied with the concentration of organisms against which it was tested; the product of the number of organisms used and the titre at the 90 per cent. end-point was, however, constant, indicating that each organism required a constant number of antibody molecules to prevent adhesion.

\section{Identification of the substances playing a part in adhesion}

Since live Bord. pertussis do not adhere to fibroblasts fixed with alcohol and ether, and boiled Bord. pertussis do not adhere to live fibroblasts, it may be concluded that both organisms and fibroblasts carry on their surface substances 


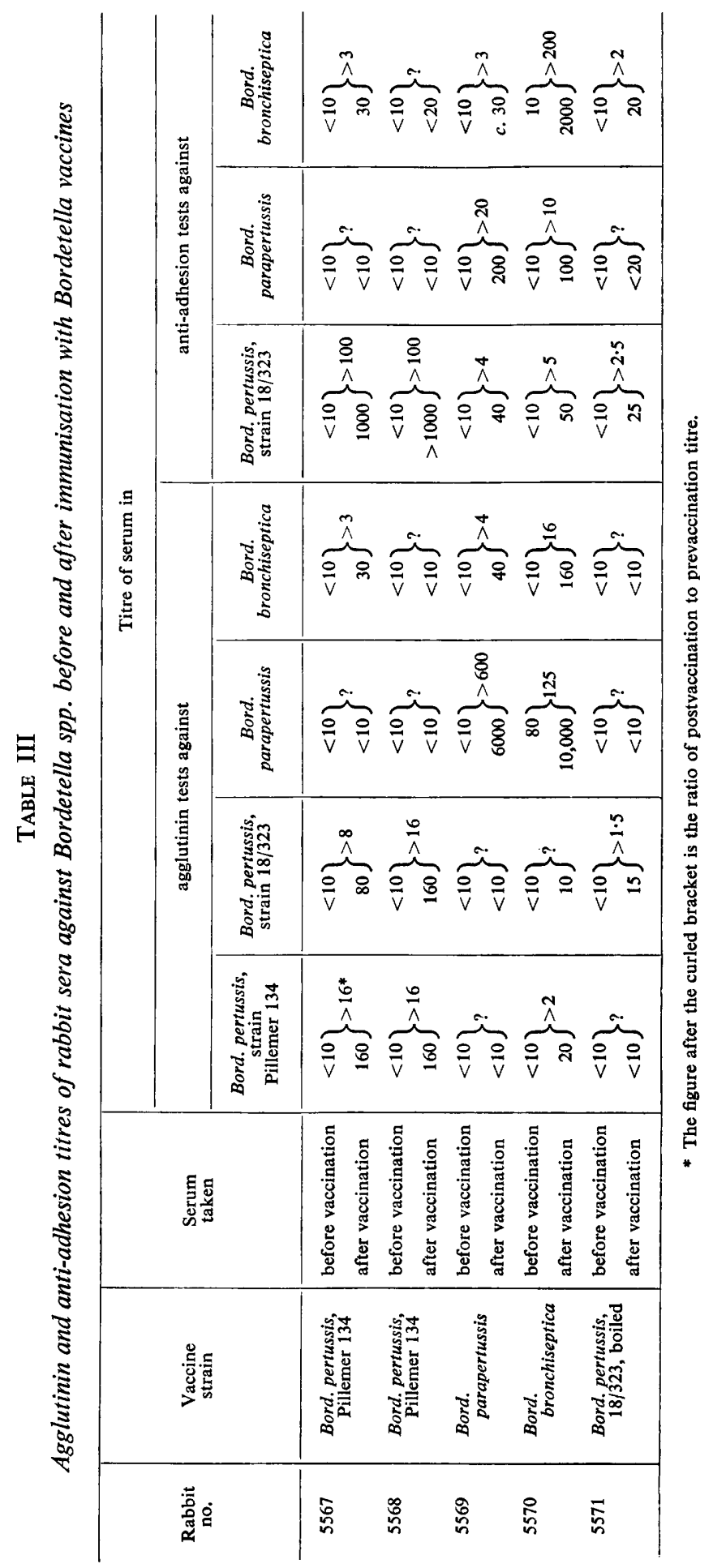


essential for mutual adhesion. These two hypothetical substances were designated $\mathrm{C}$-substance ( $\mathrm{C}$ for tissue cell) and O-substance (for organism). In order to identify the C-substance, cells were treated (" digested ") with a number of enzymes, washed with Hanks' solution, and treated with a suspension of Bord. pertussis in CA; after 4 hours' incubation of the mixture at $36^{\circ} \mathrm{C}$ the cells were examined for adhesion. The enzymes used were $\alpha$-amylase, chymotrypsin, collagenase forms I and II (from Clostridium histolyticum), deoxyribonuclease, $\beta$-glucosidase, hyaluronidase, lysozyme, proteinase, phosphodiesterase (from Crotalus adamanteus), phospholipase D (from cabbage), receptor-destroying enzyme (from Vibrio cholerae), sulphatase and trypsin.

All the enzymes with proteolytic activity, even as an impurity, caused detachment of the cells from the glass; so did hyaluronidase. Phosphodiesterase caused rapid lysis and disintegration of the cells. None of the other enzymes altered the surface of the fibroblasts so as to prevent adhesion of Bord.pertussis. But cells detached from glass by versene or hyaluronidase and washed still allowed adhesion by Bord. pertussis, whilst those detached by crystalline chymotrypsin and washed did not. Presumably the point of adhesion on the surface of the fibroblast is a protein, and possibly, since adhesion is prevented by pretreatment of the cells with the mercurial preservative Thiomersal even in sublethal concentrations, a thioprotein.

Treatment of Bord.pertussis with a wide range of enzymes failed to destroy the hypothetical O-substance. Thiomersal appeared to have a strong antiadhesive effect on both organisms and cells. To determine whether the O-substance was a lipopolysaccharide, high-titre Bord. pertussis antisera were absorbed with the specific lipopolysaccharide, but, despite the formation of a large precipitate, there was no reduction in the AA titre of the serum.

\section{Experimental infection and prevention of infection of monkey trachea with Bord.} pertussis (figs. 7 and 8 )

In man, the site of infection with Bord. pertussis is the nasopharynx, but in monkeys the best substitute I could get in reasonable amount was the trachea. Moreover, since Tomasi and Bienenstock (1968) and Tomasi (1970) had concluded that significant immunity was conferred by locally produced secretory immunoglobulins, the AA titres of saliva as well as serum were measured.

The aerosol technique used (see Materials and methods, p. 411) was successful, but adhesion to trachea was much less than to fibroblasts and was also rather patchy.

I then attempted to determine whether the prophylactic antibody demonstrated by Spasojević's intracerebral-mix technique and by the fibroblast technique would specifically prevent adhesion of Bord. pertussis to monkey tracheal epithelium. Two antipertussis sera were chosen, one (A.1) with a high, the other (C.1) with a low titre. After correction for the density of organisms used in the spray, two dilutions of each serum were made, so that each was used at $\times 3$ and $\times \frac{1}{3}$ of the amount indicated by the fibroblast technique. 
Fig. 9 shows the results; here arbitrary + and - points on the vertical axis represent respectively " infected" and " non-infected " preparations of trachea. The results are admittedly rough, but do suggest that the mechanism, and the antibody operating, in the monkey tracheal mucous membrane are the same as those effective in mouse brain experiments and in fibroblast cultures.

\section{Experimental aerosol vaccination of a Taiwan monkey to induce local antibody production}

Influenza-virus haemagglutination-inhibitor in serum will prevent haemadsorption of influenza virus and infection of tissue cultures by it, but is not the

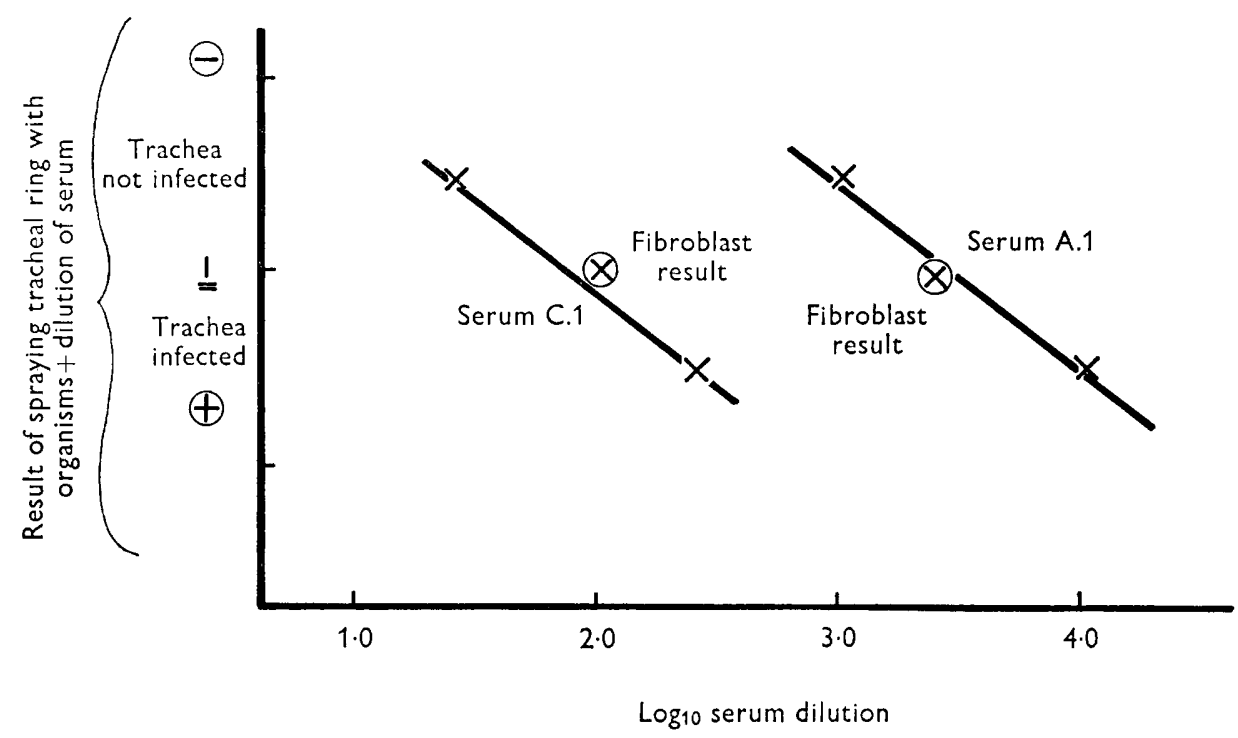

FIG. 9.-Results of spraying monkey tracheal rings with Bordetella pertussis mixed with dilutions of two antisera, one (A.1) with a high and one (C.1) with a low anti-adhesion titre. Only two dilutions of each serum were used, and the results are expressed as "infection" or "noninfection " of the trachea. "Fibroblast results" $=$ anti-adhesion titre of serum.

effective prophylactic in natural infections, where the effective antibody is made locally. Possibly a similar situation exists in Bord. pertussis infections. It was therefore necessary to produce Bord. pertussis infection with antibody response in an entire normal monkey (see Materials and methods, p. 409)

The monkey is in general a poor host for Bord. pertussis, except for the Taiwan monkey, with which Huang et al. obtained some of the few positive results. A specimen of this species was therefore obtained, and its blood and saliva were examined for AA antibody by the fibroblast technique, with negative results for both. Fourteen, 28 and 42 days after exposure to Bord. pertussis vaccine by aerosol while under sedation with Sernylan, it was bled and its serum and saliva were tested for AA antibody. Both samples gave doubtful results on all three occasions after vaccination.

On the 42nd day spray-inoculation of Bord. pertussis vaccine was repeated; 
14 days later the serum gave an AA titre of 5, the saliva one of 9. Three weeks later the monkey was again sprayed; 14 days afterwards neither serum nor saliva had any detectable AA activity. Two months later, one child-dose of pertussis vaccine was injected intramuscularly into the monkey; 14 days after this, the serum AA titre was 20 , but the saliva had no detectable AA activity.

\section{The different types of infection of mouse brain by Bordetella pertussis}

Before I attempt to integrate all the data relevant for a comprehensive account of the immunopathology of whooping cough, a close examination of the results of experimental work on Bord. pertussis infection in mice is essential.

The use of mouse brain for studies on the pathology and immunology of Bord. pertussis infection was introduced by Kendrick et al. (1947). Intracerebral infection of mice is of at least four different types, depending on the virulence of the Bord. pertussis strain for mice and on whether or not the mouse is immune. The most informative data for mouse-brain infections are the log viable counts of Bord. pertussis per brain plotted against time after infection.

If the infecting strain is virulent and the mouse normal, the log viable count per brain follows the form of fig. 10, curve 4 . There is an initial apparent loss of 90 per cent. in the number of organisms, followed by a 4-hr interval during which the count is stationary; the count then rises by c. $0.8 \log$ per day until on the 6 th -7 th day it reaches $10^{7}-10^{8}$ per brain-the constant lethal count for mice, which is independent of the size of the initial inoculum (Standfast and Dolby, 1961; Adams, 1968).

If the organisms injected are virulent and the mouse is either passively or actively immune, the log viable count follows fig. 10, curve 3 . There is no difference between the viable brain-counts of normal and immune mice for the first 4 days after challenge. At the 4 th day the count in the brain of the immune mouse begins to decrease, and the brain is virtually sterile by the 6 th -7 th day. The brain viable count at which the decrease begins is, like the lethal viable count, a constant at about 105-106 organisms (Brown, 1958; Dolby and Standfast, 1958); it is at about this time that a breakdown in the blood-brain barrier occurs, with passage of polymorphs and plasma protein into the ventricles (Holt et al., 1961).

If the organisms are non-virulent and the mouse normal, the log viable count follows the form in fig. 10, curve 2; there is the usual 90 per cent. loss of organisms, followed by an increase and then a rapid disappearance. The time taken for the slope of the log viable count curve to change its directionc. $30 \mathrm{hr}$-is independent of the size of the inoculum, but the time taken to sterilise the brain is not. In this case there is no breakdown of the blood-brain barrier.

If an incubated mixture of live organisms and sufficient immune serumthe i.c.-mix of Spasojević-is injected intracerebrally, there is no evidence that infection ever occurs (fig. 10, curve 1); the normal 90 per cent. drop in viable count continues until the brain is sterile at $c$. 1-2 days. 
Evidence for a distinction between prophylactic and therapeutic antibody

The first evidence for two possible types of immunity in the mouse was given by Dolby and Standfast, who showed that the protection given by active or passive immunisation against intranasal challenge was different from that given by passive intraperitoneal immunisation after intracerebral challenge.

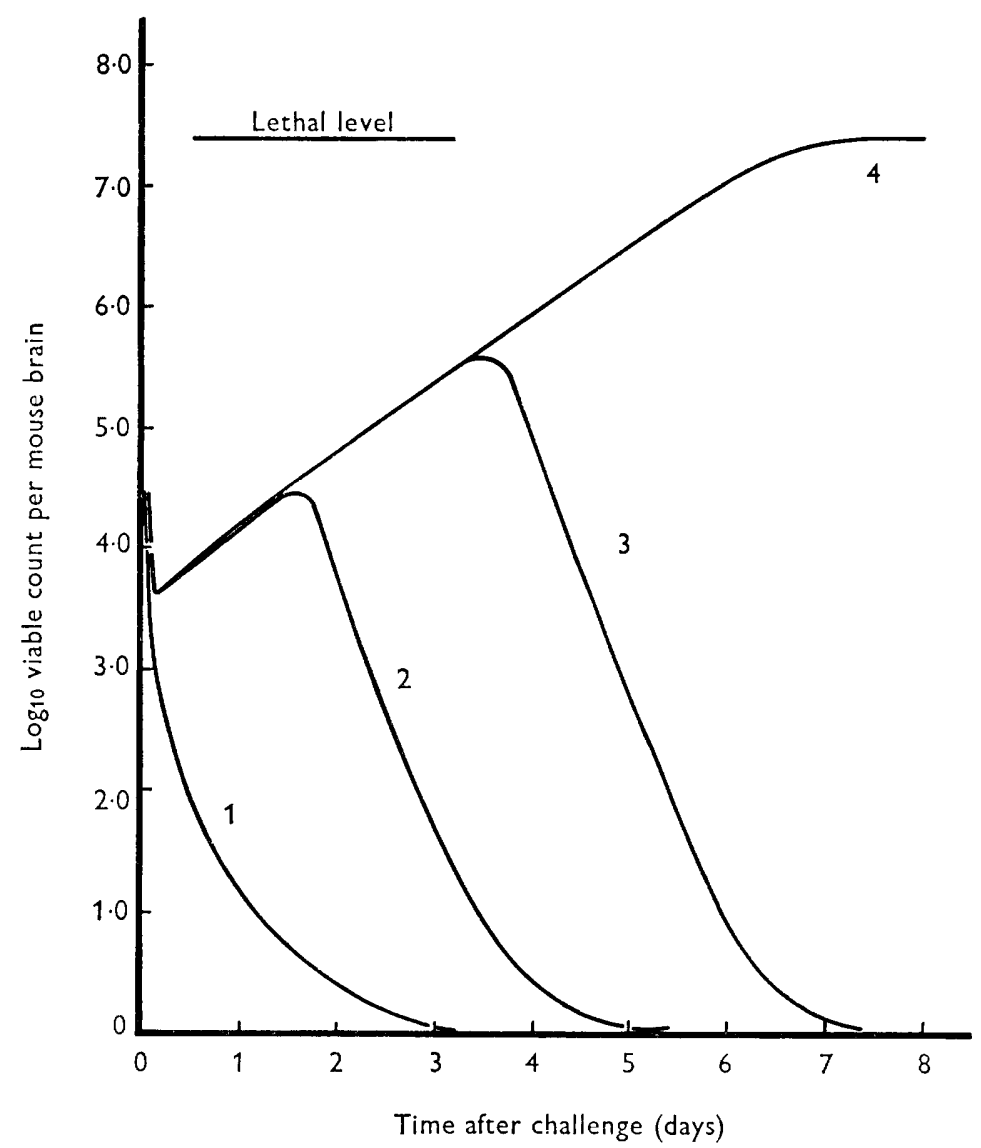

FIG. 10.-Viable counts in mouse brain after intracerebral injection of Bordetella pertussis in various circumstances.

Curve 1: viable counts after injection of virulent organisms plus adequate immune serum. Curve 2: viable counts after injection of non-virulent organisms into a normal mouse.

Curve 3: viable counts after injection of virulent organisms into an immune mouse.

Curve 4: viable counts after injection of virulent organisms into a normal mouse.

The report by Spasojević on her i.c.-mix technique was supplemented by experiments to determine the events that occur in the mouse brain after injection of such mixtures. These showed (1) that 4 days after injection, at the time when the viable count in actively or passively immunised mice was maximal, many brains were sterile, and that (2) the percentage of sterile brains in such groups of animals was equal to the percentage of mice surviving in similar groups 
(Spasojević and Holt, 1962). Later, Adams found that incubated mixtures of inactivated immune serum and live Bord. pertussis failed to cause even a temporary infection, as determined from viable counts of the brain taken from $1 \mathrm{hr}$ after intracerebral injection. There are thus two quite different immunity systems: (i) a true prophylactic system whereby infection is prevented, and (ii) a therapeutic system whereby an established infection is eliminated by phagocytic action (Adams and Hopewell, 1970). This did not, however, exclude the possibility that the same antibody might be effective in both circumstances.

TABLE IV

Titres of rabbit sera in three different passive protection tests against Bordetella pertussis

\begin{tabular}{l|l|c|c}
\hline \multirow{2}{*}{ Serum } & \multicolumn{2}{|c}{ Titre of serum in passive protection by } \\
\cline { 2 - 4 } & the i.p./i.c. test* & the i.c.-mix test ${ }^{*}$ & the anti-adhesion test \\
\hline & & 4 & 100 \\
C.1 & 1 & 6 & 250 \\
6660 & 1.4 & 4 & 250 \\
L.B.H. & 0.33 (estimated) & 8 & 750 \\
E.2 & 0.33 (estimated) & 10 & 500 \\
A.1 & 1.7 & 30 & 3000 \\
R.4 & 1.7 & 10 & 1000 \\
5708 & 10 & 35 & 4000 \\
\hline
\end{tabular}

* In this test, mice are given serum intraperitoneally and infected intracerebrally thereafter; the titres are the reciprocals of the PD50 (ml).

$\dagger$ In this test, a mixture of organisms and a dilution of serum is injected intracerebrally into mice; if a dilution of 1 in $x$ saves half the mice, the titre of the serum is said to be $x$.

Correlation coefficients:

(1) results of i.p./i.c. test against those in i.c.-mix tests: $r=0 \cdot 37, \mathbf{P}>0 \cdot 2$;

(2) results of i.p./i.c. tests against those in AA tests: $r=0.44, \mathbf{P}>0.2$;

(3) results of i.c.-mix tests against those in AA tests: $r=0.99, P<0.001$.

To check this possibility, eight different antipertussis sera were assayed for their protective values by three techniques: (1) by intracerebral challenge after intraperitoneal passive immunisation; (2) by the i.c.-mix technique and (3) by determining their AA titres for cultures of live fibroblasts. Table IV shows that the only important correlation is that between the i.c.-mix titres and the AA titres (see also fig. 11).

The conclusions from these experiments are (1) that the therapeutic antibody responsible for eliminating an established infection is distinct from that responsible for protection in the i.c.-mix technique and for the anti-adhesive effect; (2) that the anti-adhesive antibody is the same as that effective in the i.c.-mix technique.

\section{Therapeutic immunity in the infected mouse brain}

Two main findings may be adduced to account for the elimination of intracerebral Bord. pertussis infection in the immune mouse. The more important one is illustrated in fig. 2, curve 3. This shows that up to the 4th day after 
challenge there is no difference in the degree of bacterial infection in the brains of normal and immune mice; the viable count in both on the 4th day is $(0 \cdot 5-1 \cdot 0) \times 10^{6}$ organisms per brain. At this time, however, the count in the immune animals begins to decline and is practically nil by the 6 th-7th day. But it is also on the 4th day that the blood-brain barrier breaks down, with inflow of plasma proteins and polymorphs into the brain, both in immune and normal mice.

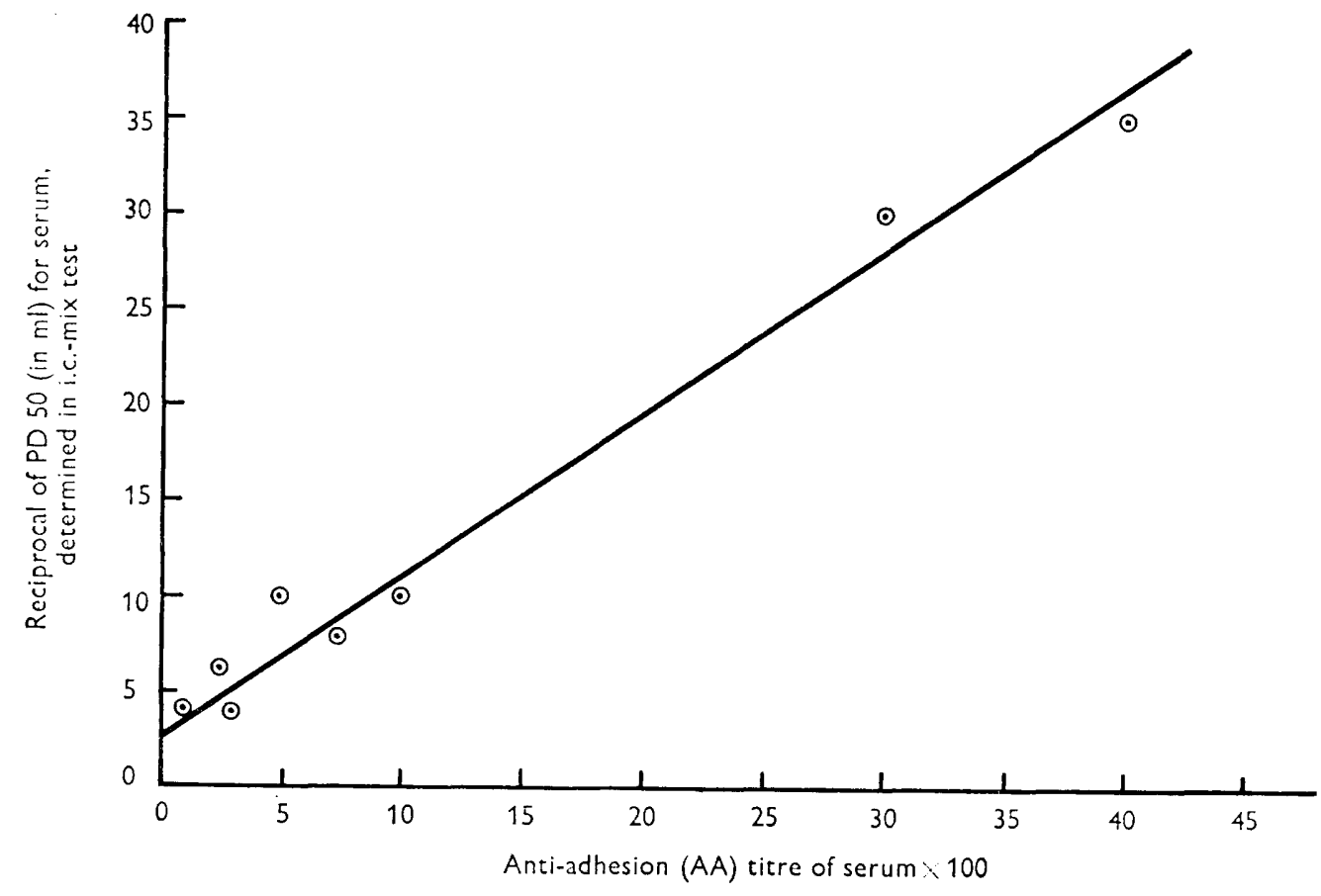

FIG. 11.-Relation between - $\log _{10}$ PD50 of eight different Bordetella petussis antisera, estimated by the i.c.-mix technique, and the anti-adhesion titres.

The second finding is that of Adams (1970) and of Adams and Hopewell (1970) on mouse brain infection. Their technique was to use strains of Bord. pertussis virulent and non-virulent for mice, and selectively to destroy brain phagocytes or blood phagocytes, the first by strictly controlled X-irradiation of the mouse head with the body screened, the second by similar irradiation of the mouse body with the head screened. They concluded that (1) brain phagocytes cannot kill mouse-virulent Bord. pertussis strains, but can kill avirulent strains, and (2) circulating polymorphs cannot phagocytose (and kill) either virulent or non-virulent Bord. pertussis except when an opsonin is present.

The site of infection with Bord. pertussis

A recent electron-microscope study (Hopewell, Holt and Desombre, 1971) of intraventricular infection with Bord. pertussis has shown that the bacteria adhere not, as had previously been supposed, to the ependymal cilia but to the 
microvilli between them, which are normally invisible in the light microscope. An additional finding of some importance is that the organisms are phagocytosed not only by neuroglial cells-apparently without complete detachment from the infected ependyma-but by the ciliated cells also.

\section{DisCUSSION}

\section{Adhesion of Bordetella pertussis to cell surfaces}

Investigation of the capacity of Bordetella pertussis to adhere to tissueculture cell-lines of MRC-5 fibroblasts and to the epithelium of monkey trachea has shown that the process of infection with Bord. pertussis is reasonably comparable to the adsorption of influenza virus on red cells (Hirst, 1941, 1942a and $b$; Gottschalk, 1958) and that two substances, one on the cell (C-substance, possibly a thioprotein), and another on the organism (O-substance), are necessary for adhesion. The facts that Bord. pertussis adheres to human fibroblasts, monkey tracheal epithelium and the neoplastic cell Hep 2 (but poorly or not at all to the neoplastic cell $\mathrm{HeLa}$ ), and that adhesion to such cells is not a universal character of bacteria, suggest that a biochemical process is involved in adhesion. Electrical attraction is possible in the early stages, but is excluded in the later ones, because particles suspended in a protein solution become coated with a film of the protein and therefore acquire a uniform electric charge (Abrahamson, Moyer and Gorin, 1942) -in these later stages chemical bonds must be far stronger. Further insight into this problem depends on identification of the substances concerned.

\section{Prevention of reinfection: true prophylaxis}

It is clear from fig. 10, curve 1, that if a mixture of live Bord. pertussis and sufficient immune mouse serum is injected intracerebrally into mice, no infection occurs (Adams, 1968; Adams and Hopewell, 1970). Moreover, the antibody that prevents infection in mice so treated is the one responsible for preventing adhesion of Bord. pertussis to human fibroblasts or monkey tracheal epithelium; and it seems probable, and in accord with the work of Tomasi and Bienenstock (1968) and Tomasi (1970) on secretory immunoglobulins, that as in immunity to influenza virus, reinfection is prevented by locally produced IgA antibody that prevents adhesion of the bacterium (or virus) to epithelium. This antiadhesive mechanism is greatly improved by the continuous flow of mucus over the surface. Incidentally, it is significant that a Taiwan monkey, previously stimulated by aerosol vaccination to produce both humoral and locally produced secretory AA antibody, failed, when given an intramuscular booster dose of Bord. pertussis vaccine, to produce any detectable salivary AA antibody. This suggests that there may be little point in giving influenza virus vaccine as a booster dose by parenteral injection.

The paradoxical implication of this is that prophylactic immunity may be self-limiting, because organisms prevented from adhering to cells by AA antibody are washed away in the mucus stream, and cannot act as an effective antigen. 


\section{Elimination of an established infection}

In immune mice, as shown in fig. 10, curve 3, established intracerebral Bord. pertussis infection does not begin to diminish until the viable count has reached $10^{5}-10^{6}$ per brain, at which level the blood-brain barrier is breached, with the admission of plasma proteins and polymorphs to the infected ventricles. This, and the demonstration that immune mice deprived of circulating polymorphs succumb to intracerebral infection with Bord. pertussis, whereas nonirradiated animals survive, leads to the conclusion that in therapeutic immunity in such mice the effective factors are circulating polymorphs and an opsonin. If this is true, it should be possible to show that normal mouse blood is not bactericidal for Bord. pertussis but that the blood of an immune mouse is, and that the difference is due to the presence of an opsonin in the blood of the immune animal. Attempts have been made to do this experiment in more than one laboratory, but there seems to be unusual technical difficulty in working with mouse leucocytes.

It is reasonable to compare tissue inflammation, in which there is capillary leakage of plasma proteins and leucocytes, with breakdown of the blood-brain barrier. It is easy to produce inflammation, but far from easy to break the blood-brain barrier-indeed, if the choroid plexus and brain capillaries were not so sensitive to poisoning by Bord. pertussis there would be no mouse intracerebral test for pertussis immunity. Local inflammation probably does occur in whooping cough, and may be due to the strongly inflammatory dermonecrotic toxin produced by Bord. pertussis.

The current practice of vaccinating infants subcutaneously with Bord. pertussis vaccines that have been controlled by the immunisation of mice subjected to intracerebral challenge may induce not a prophylactic but a therapeutic immunity. In other words, such vaccination may lead not to protection against infection but to an accelerated elimination of the infection. The results will be a great reduction in the frequency of severe cases of whooping cough, an increased frequency of mild and apparently abortive cases, and an increase in apparently complete protection. To confer true prophylaxis against whooping cough it might be necessary to add aerosol vaccination to the present immunisation programme. It should perhaps be stressed that circulating antiadhesion antibody provoked by injected pertussis vaccines cannot play any part in whooping cough prophylaxis.

\section{SUMMARY}

Strains of Bordetella pertussis, Bord. parapertussis and Bord. bronchiseptica adhered readily to live cultures of human fibroblasts. Sera from animals immunised against Bord. pertussis contain antibodies that specifically prevent the adhesion of Bord. pertussis to the cells. Anti-adhesion antibodies will not detach Bord. pertussis already adherent to fibroblasts. Limited experiments suggest that the same conclusions are true for Bord. pertussis and monkey tracheal epithelium. It is concluded that the adhesion of Bord. pertussis to 
cells depends on a biochemical mechanism, and is analogous to the adsorption of influenza virus on red cells.

Titres of anti-adhesion antibody in blood and saliva show little correlation, and it seems probable that there are two immunity systems in whooping cough: (a) a true prophylactic immunity in which locally produced IgA secretory immunoglobulin prevents the adhesion of the organism to the mucous membrane; and $(b)$ a therapeutic system, involving polymorphs and an opsonin, which after the development of inflammation acts at the surface of the membrane and eliminates the infection.

The current practice of parenteral vaccination would seem to induce the latter type of immunity, the infection itself the former type.

I wish to thank Dr G. Sander for a supply of exceptionally good Giemsa's stain and for help with microscopy, Mr J. P. Jacobs for the tissue cultures of MRC-5 fibroblasts, Miss June Ridley for the histological preparations of monkey trachea, and Dr W. D. Brighton for the excellent photomicrographs. Grateful thanks are due to the Sir Halley Stewart Trust for a substantial contribution towards the cost of the colour plates.

This work was described in an Almroth Wright Lecture, given at the Wright-Fleming Institute, St Mary's Hospital Medical School, London W.2, on the 10th May 1971.

\section{REFERENCES}

Abramson, H. A., Moyer, L. S., AND GorIN, M. H. 1942. Electrophoresis of proteins and the chemistry of cell surfaces, New York, pp. 13 and 14, figs. 1 and $1 a$.

Adams, G. J. 1968. Experimental infection with Bordetella pertussis in the mouse brain. Ph.D. Thesis, Univ. London.

AdAMS, G. J. 1970. Intracerebral infection of mice with high virulence and low virulence strains of Bordetella pertussis. J. Med. Microbiol., 3, 1 .

Adams, G. J., AND Hopewell, J. W. 1970. Enhancement of intracerebral infection of mice with Bordetella pertussis. J. Med. Microbiol., 3, 15.

Bell, J. A., Ward, T. G., Kapikian, A. Z., Shelokov, A., Reichelderfer, T. E., AND HUEBNER, R. J. 1957. Artificially induced Asian influenza in vaccinated and unvaccinated volunteers. J. Amer. Med. Assoc., 165, 1366.

Berenbaum, M. C., Ungar, J., and SteVens, W. K. 1960. Intracranial infection of mice with Bordetella pertussis. J. Gen. Microbiol., 22, 313.

Brown, ANNIE M. 1958. Intracerebral infection of mice with Haemophilus pertussis and passive protection by hyperimmune rabbit sera. J. Gen. Microbiol., 18, 48.

Dolby, Jean M., AND Standfast, A. F. B. 1958. A comparison of passive protection tests against intranasal and intracerebral challenges with Bordetella pertussis. Immunology, $1,144$.

GotrschalK, A. 1958. The influenza virus neuraminidase. Nature, Lond., 181, 377.

HIRST, G. K. 1941. The agglutination of red cells by allantoic fluid of chick embryos infected with influenza virus. Science, N.Y., 94, 22.

HIRST, G. K. 1942a. The quantitative determination of influenza virus and antibodies by means of red cell agglutination. J. Exp. Med., 75, 49.

HiRst, G. K. 1942b. Adsorption of influenza hemagglutinins and virus by red blood cells. J. Exp. Med., 76, 195.

Holt, L. B. 1962. The growth-factor requirements of Haemophilus influenzae. J. Gen. Microbiol., 27, 317.

Holt, L. B. 1968. Pitfalls in the preparation of monotypic agglutinating antisera for Bordetella pertussis. J. Med. Microbiol., 1, 169 (particularly table IV).

Holt, L. B., Spasojević, Vera, Dolby, Jean M., and Standfast, A. F. B. 1961. Immunity in mice to an intracerebral challenge of Bordetella pertussis. J. Hyg., Camb., 59, 373. 
Hopewell, J. W., Holt, L. B., AND Desombre, T. R. 1972. An electron-microscope study of intracerebral infection of mice with low-virulence Bordetella pertussis. J. Med. Microbiol., 5, 154.

Huang, C. C., Chen, P. M., Kuo, J. K., Chiu, W. S., Lin, S. T., Lin, H. S., AND Lin, Y. C. 1962. Experimental whooping cough. New Engl. J. Med., 266, 105.

Ima, T., Kusano, N., Yamamoto, A., AND Shiga, H. 1962. Studies on experimental infection with Bordetella pertussis. Bacteriological and pathological studies on the mode of infection in mouse brain. Jap. J. Exp. Med., 32, 471.

Kendrick, Pearl L., Eldering, Grace, Dixon, M. K., and Misner, J. 1947. Mouse protection tests in the study of pertussis vaccine. A comparative series using the intracerebral route for challenge. Amer. J. Publ. Hlth, 37, 803.

Meiklejohn, G., Kempe, C. H., Thalman, W. G., and LenNette, E. H. 1952. Evaluation of monovalent influenza vaccines. II. Observations during an influenza A-prime epidemic. Amer. J. Hyg., 55, 12.

Miller, J. J., JR, AND Silverberg, Rosalie J. 1939. The agglutinative reaction in relation to pertussis and to prophylactic vaccination against pertussis with description of a new technic. J. Immun., 37, 207.

Pillemer, L., Blum, Livia, AND Lepow, I. H. 1954. Protective antigen of Haemophilus pertussis. Lancet, 1, 1257.

Rich, A. R. 1932. On the etiology and pathogenesis of whooping cough. Bull. Johns Hopkins Hosp., 51, 346.

SpasoJeVIĆ, Vera 1962. An intracerebral-mix technique for the assay of pertussis antisera. In A round table conference on pertussis immunization. Proc. Int. Assoc. Biol. Standardn, Prague, Appendix, p. 5.

SPASOJEVIĆ, Vera, AND Holt, L. B. 1962. The mechanism of immunity towards B. pertussis in the mouse brain. In A round table conference on pertussis immunisation. Proc. Int. Assoc. Biol. Standardn, 2, 288.

Standfast, A. F. B., AND DolbY, JeAn M. 1961. A comparison between the intranasal and intracerebral infection of mice with Bordetella pertussis. J. Hyg., Camb., 59, 217.

Tomasi, T. B., JR 1970. Structure and function of mucosal antibodies. A. Rev. Med., $21,281$.

Tomasi, T. B., JR, AND Bienenstock, J. 1968. Secretory immunoglobulins. Adv. Immun., 9, 1.

TYRRELL, D. A. J. 1967. Serological studies on infections by respiratory viruses of the inhabitants of Tristan da Cunha. J. Hyg. Camb., 65, 327. 